\title{
Animal Cognition
}

May 2014, Volume 17, Issue 3, Pages 779-785

http://dx.doi.org/10.1007/s10071-013-0710-3

http://archimer.ifremer.fr/doc/00171/28217/

(c) Springer-Verlag Berlin Heidelberg 2013

The original publication is available at http://www.springerlink.com

\section{Innovative behaviour in fish: Atlantic cod can learn to use an external tag to manipulate a self-feeder}

\author{
Sandie Millot ${ }^{1, *}$, Jonatan Nilsson ${ }^{2}$, Jan Erik Fosseidengen ${ }^{2}$, Marie-Laure Bégout ${ }^{1}$, Anders Fernö ${ }^{3}$, \\ Victoria A. Braithwaite ${ }^{4}$, Tore S. Kristiansen ${ }^{2}$
}

\footnotetext{
${ }^{1}$ Ifremer, Place Gaby Coll BP 7, 17137, L'Houmeau, France

2 Institute of Marine Research, P.O. Box 1870, Nordnes, 5817, Bergen, Norway

3 Department of Biology, University of Bergen, P. O. Box 7800, 5020, Bergen, Norway

${ }^{4}$ Department of Ecosystem Science and Management, The Pennsylvania State University, 410 Forest Resources Building, University Park, PA, 16802, USA
}

*: Corresponding author : Sandie Millot, email address : sandiemillot@yahoo.fr

\begin{abstract}
:
This study describes how three individual fish, Atlantic cod (Gadus morhua L.), developed a novel behaviour and learnt to use a dorsally attached external tag to activate a self-feeder. This behaviour was repeated up to several hundred times, and over time these fish fine-tuned the behaviour and made a series of goal-directed coordinated movements needed to attach the feeder's pull string to the tag and stretch the string until the feeder was activated. These observations demonstrate a capacity in cod to develop a novel behaviour utilizing an attached tag as a tool to achieve a goal. This may be seen as one of the very few observed examples of innovation and tool use in fish.
\end{abstract}

Keywords: Innovation ; Learning ; Cognitive ability ; Tool use ; Atlantic cod ; Food acquisition

Sandie Millot and Jonatan Nilsson have contributed equally to this work.

\section{Introduction}

The feeding behaviour of fish is characterized by an adaptive flexibility (Dill 1983) and is modified by both Pavlovian (to find the food) and operant learning (to catch-manipulate the food; Warburton 2003). Despite the fact that fish are not renowned for their intelligence and 
their behaviour is often considered to be limited and much less flexible than that of higher vertebrates (Wynne 2010), they can modify their behaviour in a variety of contexts, and there is an increasing body of evidence that suggests that fish have been largely underestimated in term of cognitive ability (Brown et al. 2011). For instance, Kuba et al. (2010) recently showed that stingrays are able to use water as an agent (by creating a water current in different ways) to extract food from a pipe. Fish have also been reported to use their mouths to hold or manipulate objects in unusual ways, for example some wrasses are able to use a rock as an

\section{Materials and Methods}

\section{Experimental set up}

58 The experiment was run in the research station of Austevoll of the Institute of Marine 14 cod. The cod were held in $750 \mathrm{~L}$ tanks (water temperature $7-8^{\circ} \mathrm{C}, \mathrm{O}_{2}$ saturation $>90 \%$ ) continuously lit by a $35 \mathrm{~W}$ halogen spotlight hanging $1.5 \mathrm{~m}$ above the water surface.

There were two self-feeding devices (InnovaFeed, InnovAqua SLL, Sevilla, Spain) for each tank. A feeder device comprised an electric switch connected to a pull string (gut line) with a soft plastic bead at the end reaching about $5 \mathrm{~cm}$ under the water surface for the fish to bite and pull. Activation was registered by a computer that started an automatic feeder that fed $0.8 \mathrm{~g}$ of dry food around $60 \mathrm{~cm}$ downstream the pull string self-feeder. Each activation was automatically video recorded by a colour video camera positioned above each feeder (for more details, see Millot et al. 2012). A buffer system made it possible to start the recording 15 
$69 \mathrm{~s}$ before the activation to study who and how the trigger was activated. Unsuccessful 70 triggering attempts were therefore not recorded.

\section{Experimental fish}

73 The experimental fish were 13 months old farmed Atlantic cod first reared in a sea water pond 74 and start fed on natural zooplankton. After two months they were recaptured from the pond and transferred to sea cages and fed dry feed. Seven months before the start of the experiment, the fish were moved to indoor tanks at the IMR, Austevoll Research Station. Two days before the start of the experiment, the fish were anesthetized with a solution of $5 \mathrm{mg}^{-1}$ of methomidate (Marnil TM, Wildlife Labs, inc., Fort Collins, USA), measured for length and weight (32 $\pm 2 \mathrm{~cm}, 364 \pm 71 \mathrm{~g}$, mean $\pm \mathrm{SE}$; Focal fish: Fish 1: $35 \mathrm{~cm}, 508 \mathrm{~g}$, female (Tank 2); Fish 2: $32.5 \mathrm{~cm}, 385 \mathrm{~g}$, male (Tank 3); Fish 3: $34.5 \mathrm{~cm}, 495 \mathrm{~g}$, male (Tank 3)). For more information about size, sex and feeder activation of all individuals in the tanks, see Table 1 in Millot et al., 2012, where the focal fish corresponds to Fish 2-1 (Fish 1), Fish 3-2 (Fish 2) and Fish 3-4 (Fish 3). All fish were marked with an external t-bar tag with a coloured bead attached $(10 \mathrm{~mm}$ in diameter; $0.5 \mathrm{~g})$, stitched in the muscle on the right side of their anterior dorsal fin (Fig 1A). During the 2-day recovery period the fish were fed by hand ad libitum in the experimental tanks with the self-feeder strings kept outside the tank.

\section{Data analysis}

The video recordings of all feeder activations were analysed in order to identify the individuals performing trigger activations and the behaviour during activations. The variables analyzed for each focal fish were i) the cumulative number of self-feeder activations in relation to time, performed either with the mouth or using the tag (colour bead), ii) the latency to reach the feeding zone (just below the feeder, where the pellets fell into the water) after activation of the self-feeder with the tag and iii) the percentage of clockwise or anticlockwise rotation direction when the fish attached the tag to the pulley to study if the behaviour became standardized. To track the swimming pattern before, during and after feeder activation in early and late tag activations, the 7 first and the 7 last tag activations of each focal fish were analyzed in more detail. A coordinate system drawn on a transparent sheet was placed on the screen with the feeder pulley at origo, and the coordinates of the tag was plotted with $0.4 \mathrm{~s}$ interval (i.e. 10 frames) from $0.8 \mathrm{~s}$ before to $4.8 \mathrm{~s}$ after the tag was entangled to the pulley to create a picture of the swimming pattern. 
Correlation between activation number and latency to reach the feeding area was tested by Kendall's tau rank correlation. Statistical analyses were performed using R software system Version 2.12.0 (Copyright 2010, The R Foundation for Statistical Computing, Vienna, Austria).

\section{Results}

\section{The behaviour during feeder activation}

Almost all of the fish activated the feeder during the experiment (48 out of 56, Millot et al. 2012) by first approaching and then biting the pull string bead and swimming forwards (Video sequence 1), which is the behaviour the feeder device is constructed for. Three individuals from two different tanks (Fish 2 and 3 in the same tank) seemingly accidentally entangled their tag into the trigger pulley (Fig 1A), resulting in activation of the feeder (Video sequence 2). Presumably startled at being attached to the pulley, the fish responded with a fast burst of swimming until the tag became unhooked. In these first occasions of activation with the tag the fish did not immediately return to feed (Fig 2A). The behaviour when attaching the tag to the pulley eventually changed to a goal-directed behaviour, and after fine-tuning, all three fish were able to perform a series of coordinated movements needed to activate the feeder using the dorsal tag alone (Video sequence 3 ). The cod first adjusted its position by slow swimming movements, then with great precision attached the bead of the tag to the trigger pulley and finally swam forwards before turning to release itself (Fig. 1B). At the end of the experiment the three focal fish showed standardized swimming patterns to catch the trigger with their tag, activate the feeder and reach quickly the feeding zone (Fig 2B).

\section{Number of mouth and tag activations}

Fish 1 performed its first feeder activation with the mouth on Day 1 but became more active from Day 4 (12 activations) onwards. At Day 4, this fish performed its first feeder activations with the tag (20 activations). From Day 8 onwards Fish 1 used the tag more often than the mouth to activate the feeder (hereafter called method switch), and after Day 11 it never used the mouth again. At the end of the experiment, Fish 1 had in total performed 51 feeder activations with the mouth and 422 feeder activations with the tag (Fig. 3A).

Fish 2 activated the feeder for the first time on Day 1, with 19 mouth activations and 1 tag activation. From Day 17 onward the frequency of tag activations increased markedly with a 134 method switch that day. At the end of the experiment, Fish 2 had in total activated the feeder 13596 times with the mouth and 195 times with the tag (Fig. 3A). 
Fish 3 performed its first feeder activation with the mouth on Day 1. The first activation with the tag was done on Day 17 after 24 cumulative feeder activations with the mouth. Until the end of the experiment, this fish mainly activated the feeder with the mouth, but had a method switch on Day 27 with 28 activations with the tag and only 9 with the mouth. At the end of the experiment, Fish 3 had performed 55 activations with the mouth and 37 with the $\operatorname{tag}$ (Fig. 3A).

\section{Latency to reach the feeding zone}

A rapid decrease in latency time between tag activation and reaching the feeding zone (Fig. 3B) coincided with the switch in activation technique (Fig. 3A). The mean latency to reach the feeding zone decreased with activation number for all three individual (Kendall's tau correlation, Fish 1: tau $=-0.31, \mathrm{p}<0.001$; Fish 2: tau $=-0.51, \mathrm{p}<0.001$; Fish 3: tau $=-0.70$, $\mathrm{p}<0.001$ ). The mean latencies before the method switch were $3.2 \pm 2.0 \mathrm{~s}$ (Fish 1), $3.9 \pm 2.0 \mathrm{~s}$ (Fish 2) and $5.9 \pm 2.3 \mathrm{~s}$ (Fish 3) compared to $0.5 \pm 0.7 \mathrm{~s}$ (Fish 1), $0.6 \pm 1.0 \mathrm{~s}$ (Fish 2) and 1.0 $\pm 0.9 \mathrm{~s}$ (Fish 3, Fig. 3B) after the method switch.

\section{Rotation direction during tag activation}

For two of the fish the direction when approaching and actuating the trigger with the tag became more standardized after the switch in method. Fish 1 had an anti-clockwise rotation direction in $40 \%$ of the feeder activations before the switch and in $87 \%$ of the activations after it changed the way it operated the feeder. Fish 2 rotated anti-clockwise in 33\% of the feeder activation before it changed its technique and in $85 \%$ after. Fish 3 always rotated clockwise.

\section{Discussion}

Using the mouth to explore possible food objects such as the pulley of a self-feeder is a 'natural' behaviour in cod, where the association with food reinforces and increases the frequency of this behaviour by operant conditioning (Nilsson and Torgersen 2010). In this and similar experiments we have observed that frequently pulling fish refine their behaviour from initially more or less random manipulation of the "bait" to an intentional controlled bite and pull of the trigger until the food is released (Millot et al. 2012). In contrast, the first entanglement of the tag to the pull string observed in this study caused an initially aversive experience indicated by the escape response when the stretched string pulled the tag. However, since the fish learned to use this behaviour to activate the trigger, they must after 
few accidental entanglements have associated this incident with the food reward permitting the fish to learn and become operant conditioned for this novel behaviour.

Over time the cod seemed to develop a deliberate behaviour where the fish tried to entangle the tag to the pull string trigger to get food. The aversive sensation when the string pulled the tag could signal to the fish that the behaviour was successful, which was subsequently confirmed by the food delivery. Over time the "tag technique" was refined and became more effective, as seen by the standardized swimming behaviour and the decreased latency to reach the feeding area. Eventually, this new technique became preferred over the "mouth technique", since all three individuals eventually mostly or even exclusively activated the feeder with their tag. As we did not have the possibility to video record unsuccessful attempts, we do not know how fast the success rate of this behaviour increased. A possible reason for why the "tag method" was preferred could be that activation with the tag provided better control since the fish could focus on the food area and competitors and did not have to focus on the trigger as they did when activating with the mouth. The result was to transition an initially aversive action involving an artificial morphological feature (the tag) into an effective way to acquire food that represents a novel and amazing behaviour.

Using the definition of innovation from Ramsey et al. (2007): "Innovation is the process that generates in an individual a novel learned behaviour that is not simply a consequence of social learning or environmental induction", we believe that this novel behaviour can be seen as an innovation. The cod did not just swim to a particular location or use another normal behaviour but carefully attached the tag by fine-scale coordinated movements and repeated this behaviour a high number of times. Innovations are not necessarily cognitively complex (Ramsey et al. 2007), and chance events can lead to innovations if the individual learns from the experience, and when it is rewarded, the innovative act is likely to be repeated with increased efficiency (Reader 2003). What is striking with the present observation is the "behavioural accident", i.e. getting the tag attached to the feeder pulley, was presumably initially aversive and totally artificial since cod are not known to use their back or fins to manipulate objects, and that cod were yet able to fine-tune this action to a standardized technique to obtain a goal. That the fish had already activated the feeder repeatedly with the mouth before switching to the tag technique, and thus had a functional and non-aversive alternative to obtain food, makes the findings even more surprising.

In a population there may be only one innovator that finds new ways to solve a task (Weir and Kacelnik 2006), but if the method is successful it may be socially transmitted and become more common. Reader and Laland (2003) defined innovation as "a process that results in new 
203 or modified learned behaviour and that introduces novel behavioural variants into a population's repertoire". Fish 3 may have learnt the technique from Fish 2, which was in the same tank and had started to use the tag earlier, but we do not know if more individuals would adopt the new technique if the experiment had continued for a longer period.

Since fish naturally lack morphological structures to catch or manipulate object such as hooks, using an attachment of the body to manipulate an object should be considered as outside of their mental and behavioural repertoire. By introducing a morphological change (tag on the back) we gave to the fish the possibility to perform and develop a new rewarding behaviour. It may even be possible to see the use of the tag as an "artificial limb" or as a form of tool use. Tool use has been demonstrated in mammalian (Goodal 1964; Seed and Byrne 2010) and avian (Hunt 1996; van Lawick-Goodall and van Lawick-Goodall 1966; Bluff et al. 2007; Holzhaider et al. 2010) species and even in octopus (Finn et al. 2009). A widely used definition of tool use is the employment of an environmental object to alter the form, position or condition of another object, another organism, or the user itself when the user holds or carries the tool during or just prior to use (Beck 1980). However, for animals such as fishes, holding tools represents a challenge because they lack limbs that can grasp and orient a tool, and the physical properties of water further restrict tool use (Brown 2011). From a cognition point of view, however, the question is not how an animal uses a tool or an extension of the body but why, i.e. the ability to adapt a novel technique with the intention to obtain a goal novel in the sense that it does not reflect species-specific evolutionary adapted behaviour and morphology. For this reason, defining tool use as the active manipulation of an external object (here the tag) in the attainment of a goal (here the food delivery by feeder activation) is currently commonly accepted (Kuba et al. 2010; Brown 2011). If we accept that the cod were aware of the morphological extension (the tag) on the back, using this to activate a feeder could be regarded as a form of tool use according to this definition.

In conclusion, a fundamental difference exists between using a part of the body that has evolved to manipulate objects like the mouth and synchronized goal-directed body movements using a novel appendage that has had no evolutionary history. Although there is still dispute about how innovative behaviour and tool use should be defined (Ramsey et al. 2007), this novel behaviour in cod could be seen as an example of innovation and tool use.

\section{Ethical standards}


The work was conducted in accordance with the laws and regulations controlling experiments and procedures on live animals in Norway following the Norwegian Regulation on Animal

${ }_{4}^{3} 237 \quad$ Experimentation 1996.

\section{Conflict of interest}

The authors declare that they have no conflict of interest.

\section{Acknowledgements}

This study has been carried out with financial support from Institute of Marine Research, Norway, Research Council of Norway, and the Commission of the European Communities, through Cost Action 867, Short Term Scientific Mission allocated to S.M. We would like to thank Stein Mortensen for the drawings in Fig. 1. We are grateful to two anonymous referees and to editor for their valuable comments.

\section{References}

Beck BB (1980) Tool use in animals. Garland STPM Publishers, New York

Bernardini G (2011) The use of tools by wrasses (Labridae). Coral Reefs doi:10.1007/s00338011-0823-6.

Bluff LA, Weir AAS, Rutz C, Wimpenny JH, Kacelnilk A (2007) Tool-related cognition in new caledonian crows. Comparative Cognition and Behaviour reviews.2: 1-25

Brown C (2011) Tool use in fishes. Fish Fish. 13: 105-115.

Coyer JA (1995) Use of a rock as an anvil for breaking scallops by the yellowhead wrasse, Halichoeres garnoti (Labridae). Bull. Mar. Sci. 57: 548-549.

Dill LM (1983) Adaptative flexibility in the foraging behavior of fishes. Can. J. Fish. Aquat. Sci. 40: 398-408.

Finn JK, Tregenza T, Norman MD (2009) Defensive tool use in a coconut-carrying octopus. Curr. Biol. 19: R1069-R1070.

Fricke H (1971) Fische als Feinde tropischer Seeigel. Mar. Biol. 9: 328-338.

Goodall J (1964) Tool using and aimed throwing in a community of free lining chimpanzees. Nature, 201: 12-1266.

Holzhaider J, Hunt G, Gray R (2010) Social learning in new Caledonian crows. Learning \& Behavior 38: 206-19

Hunt GR (1996) Manufacture and use of hook-tools by New Caledonian Crows. Nature 379: 249-251. 
Jones AM, Brown C, Gardner S (2011) Tool use in the tuskfish, Choerodon schoenleinii ? Coral Reefs doi:10.1007/s00338-011-0790-y.

Kuba M, Byrne R, Burghardt G (2010) A new method for studying problem solving and tool use in stingrays (Potamotrygon castexi). Animal Cognition 13: 507-13

Millot S, Nilsson J, Fosseidengen JE, Bégout ML, Kristiansen T (2012) Evaluation of selffeeders as a tool to study diet preferences in groups of Atlantic cod (Gadus morhua). Aquat. Living Resour. 25: 251-258.

Nilsson J, Torgersen T (2010) Exploration and learning of demand-feeding in Atlantic cod (Gadus morhua). Aquaculture. 306: 384-387.

Ramsey G, Bastian ML, van Schaik C (2007) Animal innovation defined and operationalized. Behavioural and Brain Sciences 30: 393-437

Reader SM (2003) Innovation and social learning: individual variation and brain evolution. Animal Biology 53: 147-58

Reader SM, Laland KN (2003) Animal innovation: an introduction. In: Animal Innovation (Ed. by S. M. Reader \& K. N. Laland), pp. 3e35. Oxford: Oxford University Press.

Seed A, Byrne R (2010) Animal tool-use. Curr. Biol. 20: R1032-R1039.

van Lawick-Goodall J, van Lawick-Goodall H (1966) Use of tools by the Egyptian Vulture, Neophron percnopterus. Nature 212: 1468-1469.

Warburton, K (2003). Learning of foraging skills by fish. Fish. Fish., 4: 203-215.

Weir AS, Kacelnik AA (2006) New Caledonian crow (Corvus moneduloides) creatively redesigns tools by bending or unbending aluminium strips. Anim. Cogn. 9: 317-334.

Wirtz P (1996) Werkzeuggebrauch bei Lippfschen. Aquarium Terrarium Z1: 4-5.

Wynne C. (2010) Calibrating the scales of fish suffering. Nature 464: 981.

\section{Figure captions}

Fig. 1 Goal-directed self-feeder activation with the tag. (A) Close-up of the tag bead attaching to the self-feeder trigger pulley (i.e. gut line with a soft plastic bead at the end). (B) Four stages of a goal-directed tag activation by a cod. In a circular (anti-clockwise) movement the fish carefully approaches the trigger pulley (1), positions the trigger under the tag bead (2) and swims forwards to activate the feeder (3) and then releases the bead from the trigger and swims to the dispensed food (4). 
Fig. 2 Evolution of fishes' approaches using their tags to activate the feeder over time.

1

(

.

Track of the swimming pattern before, during and after the tag was entangled to the feeder pulley in the 7 first (A) and 7 last (B) tag activations. Origo (axis intersection) is the original position of the pulley. Big filled symbols indicate the start of the track $0.8 \mathrm{~s}$ before the tag was entangled), small filled symbols indicate where the tag was entangled to the pulley, big symbols filled with yellow indicate when the feeder was activated, arrows indicate end of the track and movement direction.

Fig. 3 Change in self-feeding behaviour across time. (A) Cumulative number of self-feeder activations, performed either with the mouth or using the tag as a pulling tool, (B) latency to reach the feeding zone after the self-feeder activation with the tag.

\section{Supplementary material}

Supplemental information includes a movie (ESM_1.mpg) demonstrating the development of the fish (Fish 1) self-feeder activation (sequence1: with the mouth, sequence 2: by accident with the tag and sequence 3: goal-directed with the tag). 
Figure $1 \mathrm{~A}$
Click here to download high resolution image

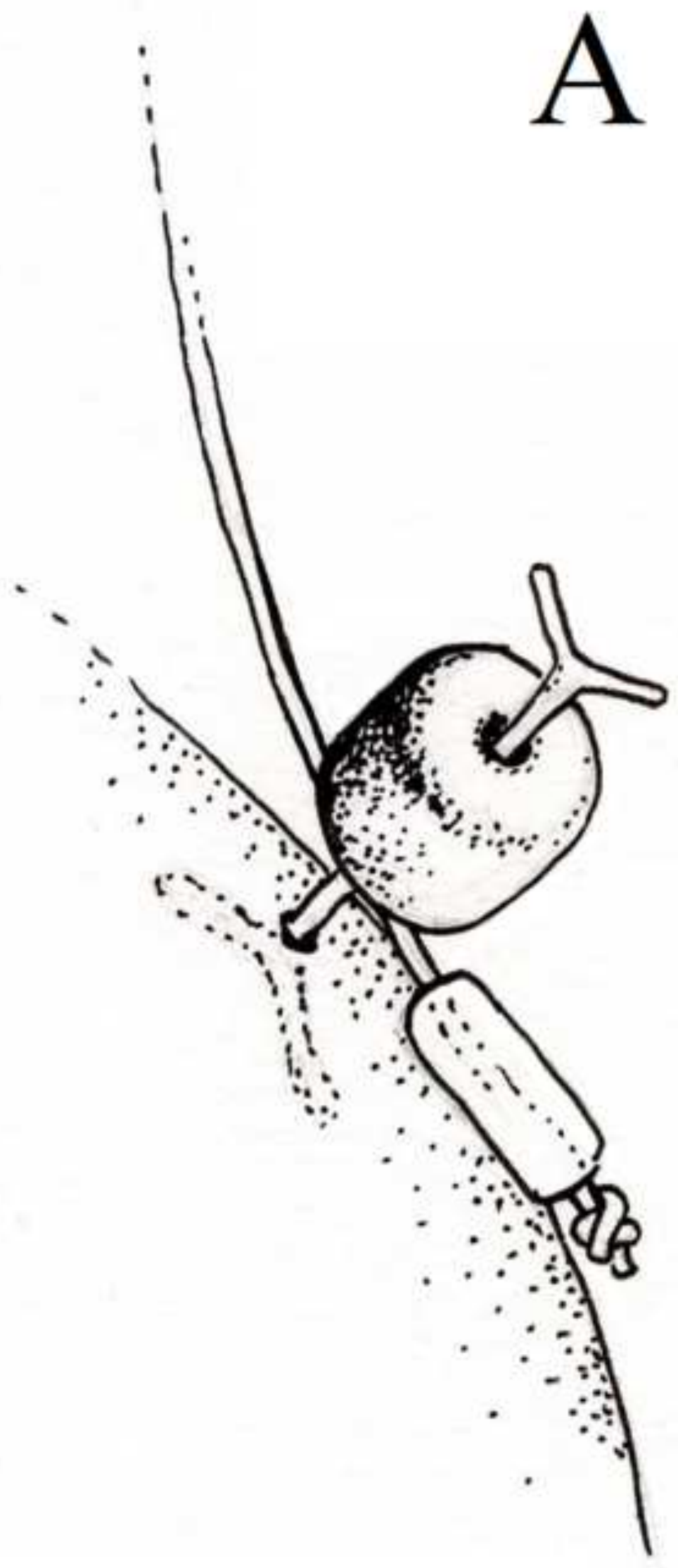


Figure 1B

Click here to download high resolution image

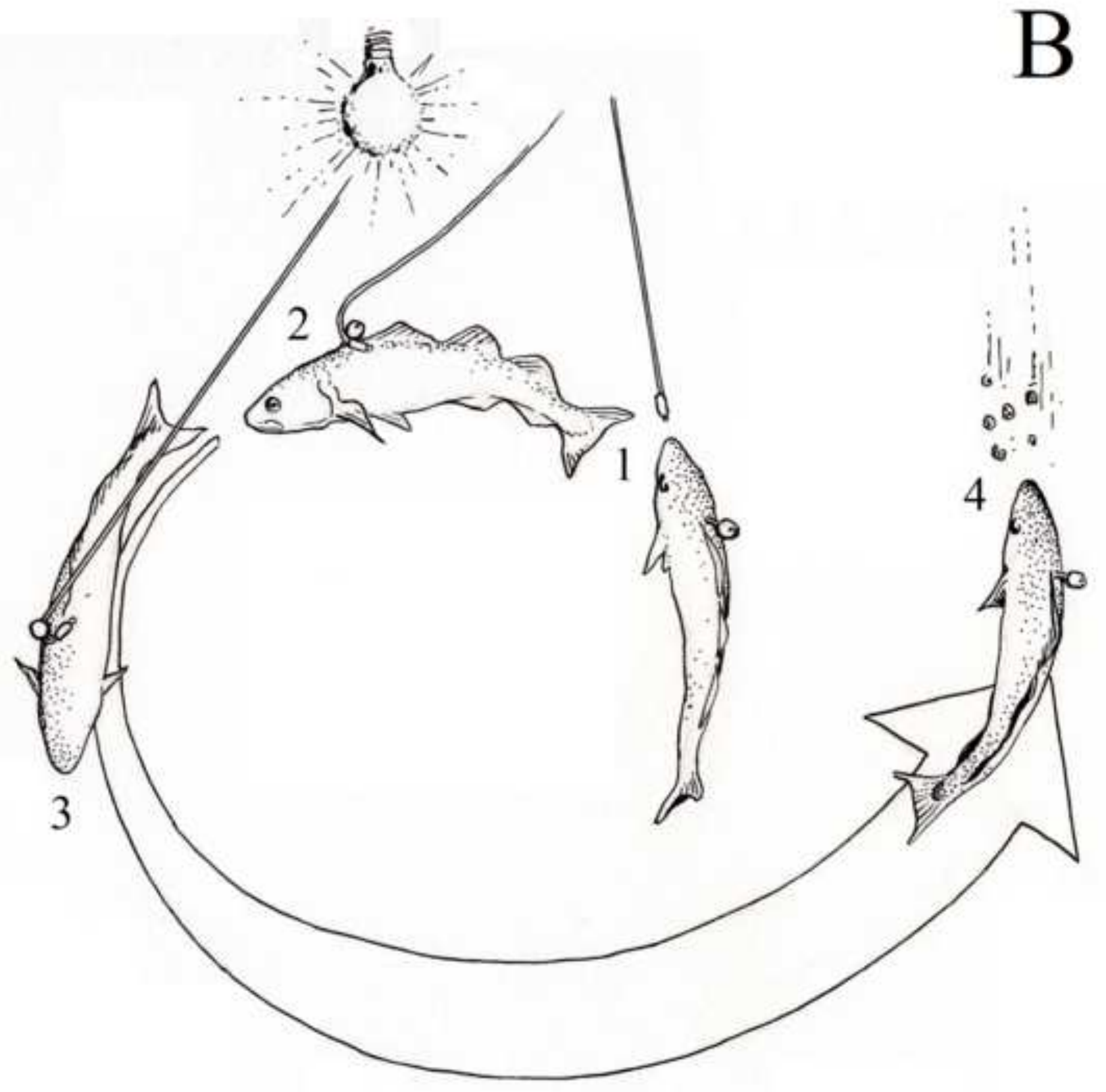


Figure 2

Click here to download high resolution image

$$
\begin{array}{r}
-1 \\
-2 \\
--3 \\
-4 \\
-5 \\
-0-6 \\
+7
\end{array}
$$

Fish 1

Fish 2

Fish 3

A
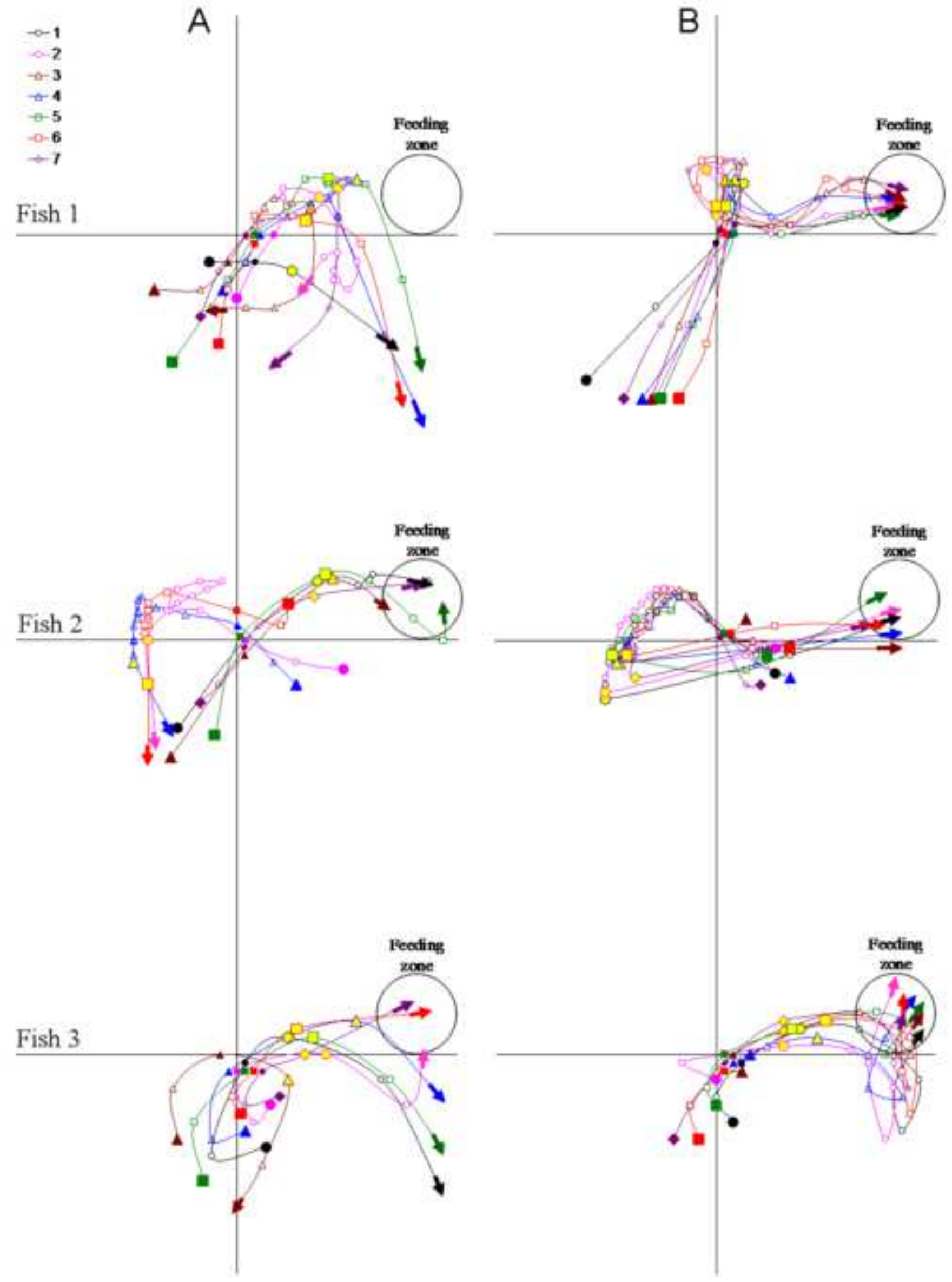
Fish 1

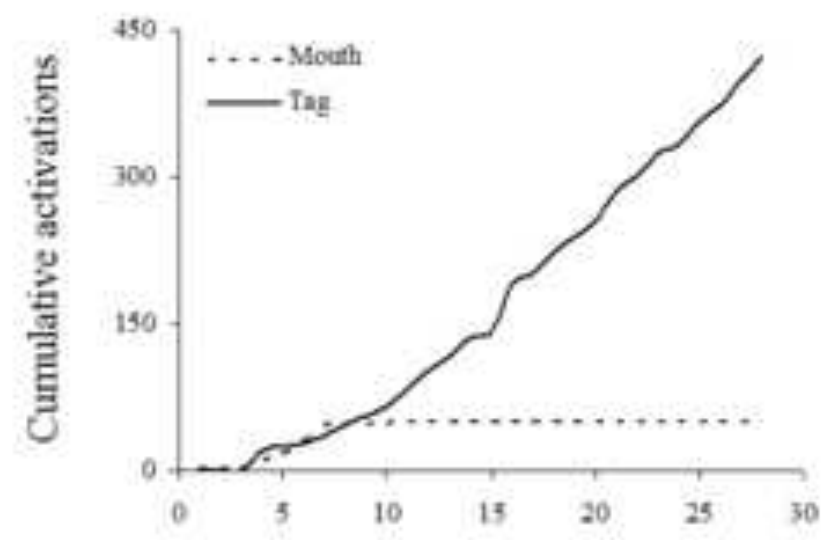

Fish 2

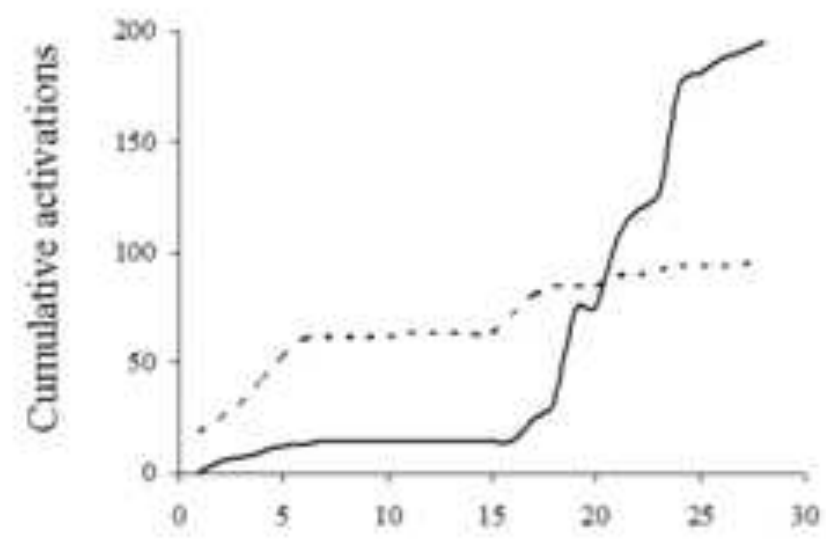

Fish 3

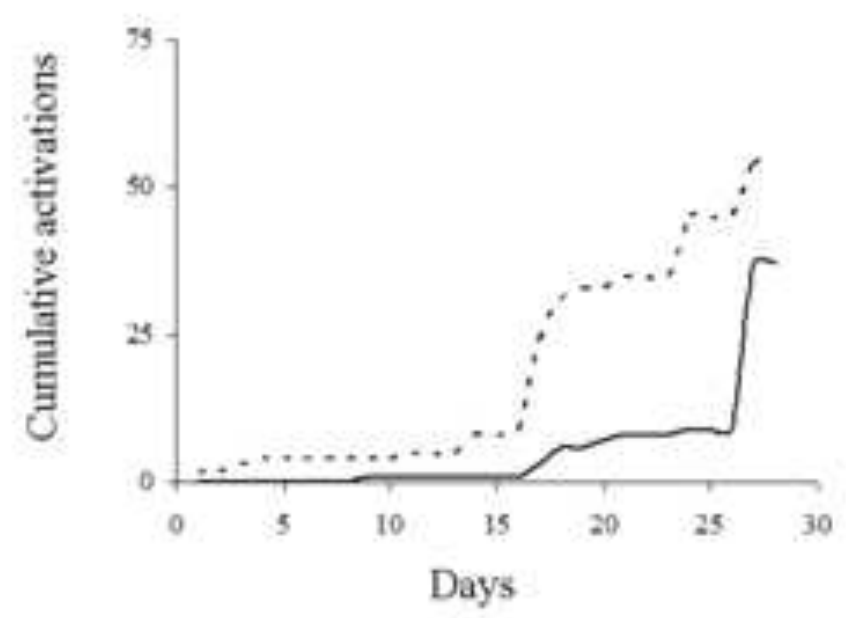

A

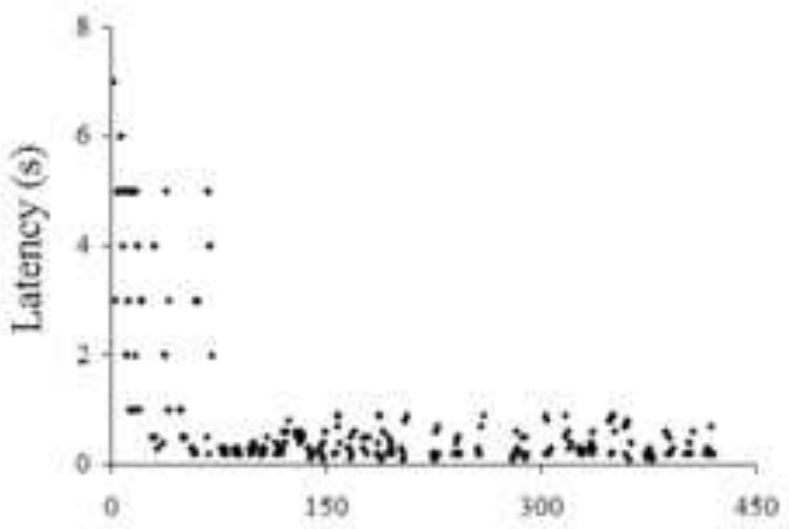

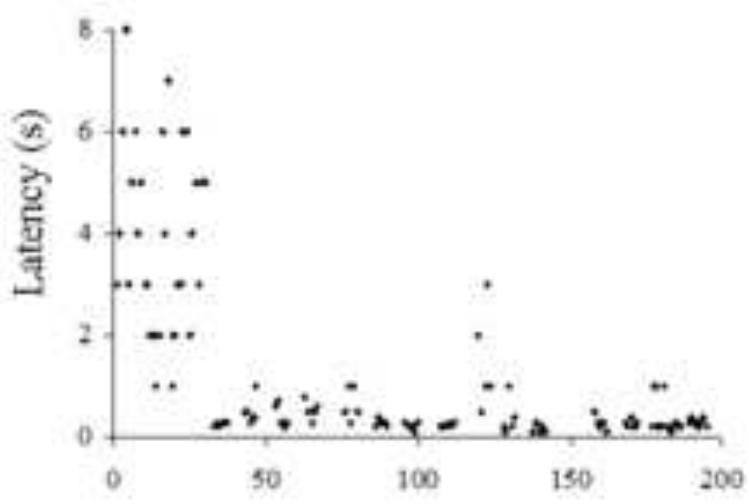

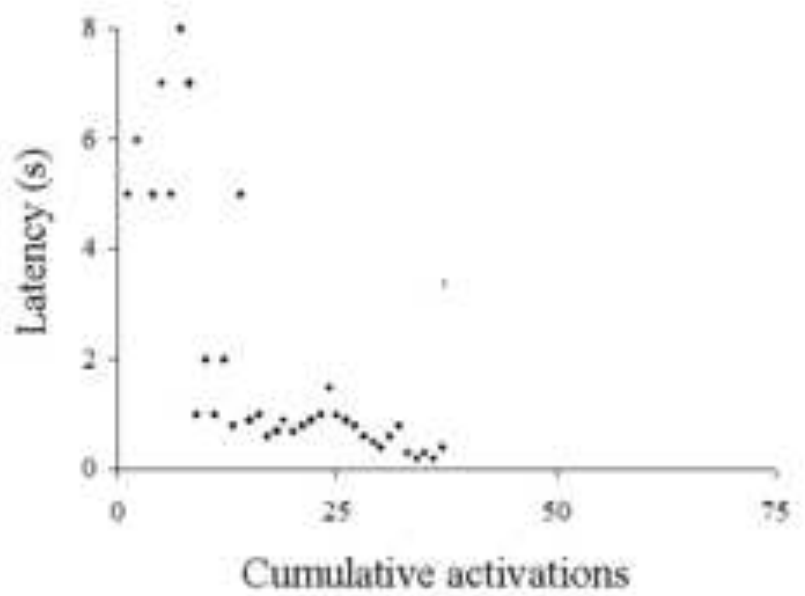


Online resource 1
Click here to download Supplementary Material: ESM_1.mpg.mpg 